\title{
National-psychological features of the motivation for higher education in different cultures: Evidence from Russia and China
}

\author{
Svetlana Murafa ${ }^{1, a *}$ \\ 1 Moscow Pedagogical State University, 119991, 1/1 Malaya Pirogovskaya str., Moscow, \\ Russia
}

amurafa.svetlana@gmail.com

${ }^{*}$ Corresponding author

Keywords: national-psychological features of motivation, ethnic psychology, psychology, motivational sphere, Chinese students, Russian students, higher education

\begin{abstract}
The article presents the results of a study of national psychological characteristics of Russian and Chinese students' motivation for higher education. The obtained results allowed to draw conclusions about the differences and similarities in the motives for obtaining higher education students have in different cultures. It is proved that the formation of their learning motivation largely depends on motivational, background, and national psychological characteristics.
\end{abstract}

\section{Introduction}

In contemporary conditions, higher education plays an important role for every person. At this stage, the Russian-Chinese cooperation is characterized by a wide range of areas, including in the field of education: an increasing number of Russian universities are becoming partners of Chinese educational institutions, which leads to an increasing number of exchange students. So, as of 2014-2015, about twenty thousand Chinese students were studying in educational institutions of Russia, and the same number of Russian students were in educational institutions of China [6].

The development of academic cooperation is a mutual vector of Russia and China. Given this fact, the study has practical and theoretical significance, allowing one to get an idea of what motives are the guided, ones, what goals and objectives are set by students of Russia and China when they receive higher education in different countries. Soviet and Russian researchers in different years studied motives and motivations: L. I. Bozhovich, A. G. Kovalev, K. K. Platonov, S. L. Rubinstein, V. A. Ivannikov, as well as in Ethnopsychology: L. M. Drobizheva, V. V. Karlov, Yu. P. Platonov, E. A. Sarakuev, V. G. Krysko. However, there are almost no works of Russian researchers that would address the problem of motivation of representatives from different countries.

We put forward the hypothesis that students of different countries are driven by different motives for getting higher education, and their formation depends on the national psychological characteristics and differences in the culture of societies of different countries.

In psychology, there are two types of motivation: external and internal. External motivation is formed and regulated by external material or psychological influences, internal motivation is due to personal needs, interests, goals. A similar interpretation of two types of motivation is given by Western (Wigfield and Schiefele, Pintrich and Schunk) and Russian researchers (A. A. Rean, N. V. Bordovskaya, S. I. Rozum, L. I. Bozhovich, and others). However, this interpretation is suitable if we are talking about the problem of formation of motivation of Western students $[5,8,9]$.

However, considering the process of formation of motivation of students of the East, it would be limited to such an interpretation of the concepts of external and internal motivation, which is not possible. Thus, in foreign scientific works dealing with the problem of motivation, the importance of intrinsic motivation is emphasized, it is often compared with the concept of "interest" and, possessing cognitive influence, has a greater effect on academic performance, increasing student results. However, the relationship between the interest and academic performance of Chinese students is an excellent and multifaceted process [10, p. 191]. 
It was established in various studies: students show high results in the subject, while their attitude to this subject is not positive. In this case, the influence comes from the two types of motivation, both external and internal, with each type having its own characteristics [10, pp. 191-192]. Intrinsic motivation can be explained as the "key" to hard work. Extrinsic motivation has a more differentiated structure and is shaped by:

- External control (promotion or punishment),

- Unconscious social coercion (to win the approval of other people),

- Self-identification through self-assessment of their values and achievements (carried out with the participation of internal control) [10, p. 191].

Self-identification in this case refers to external factors, since it is carried out by comparing itself with the standard dictated/drawn by society, as well as by the degree of conformity of its values and achievements with those accepted in society.

The relationship between internal and external motivation cannot be called clear, these two components of one process are interconnected, external factors can become internal. It may be noted a sense of responsibility and value of teaching Chinese students, their willingness to make efforts to achieve high results, even if there is no interest in subjects [10, p.192]. One of the factors in the formation of external motivation is unconscious social coercion, which is understood as a social duty to parents and family [12, $\mathrm{p}$. 13]. In addition, cultivation is emphasized in Chinese culture. The educational process is considered as selfdevelopment, in which the emphasis is on perseverance and diligence in learning, because these qualities can bring success. Thus, on the one hand, motivation is formed under the influence of a sense of duty to parents, family and society, on the other hand, an understanding of the need for education as a way of selfdevelopment, which once again underlines the relationship between external and internal motivation.

Russian students tend to explain academic success by the presence of abilities or the presence of an experienced teacher, which is less controlled by students, while Chinese students look for an explanation in internal components, for example, the degree of effort that is more controlled by students [11; 10, p. 193].

Western teachers often have to think about how to form and maintain motivation of their students and how to make the learning process more attractive so that students become aware of the meaning of these tasks. Teachers in China do not often have to stress the need for training. Even if the assignment does not seem interesting, the student will do it [10, p. 196].

Compared to Western teachers, teachers in China do not often have to emphasize the need for learning; they do not spend so much time meeting students' individual needs. Both schoolchildren and students are aware of the simple fact: if one fails, it means that more and longer must be done. Perseverance in achieving its goal is maintained in case of success and failure. According to Chinese students, a good teacher is a person who knows his subject deeply, is proficient in material, is able to answer questions, and has a certain moral concept [13]. We can conclude that motivational features also influence the formation of educational process in different cultures [3]. National-psychological features are the dynamic side of the psychology of the nation and characterize the peculiarity of the flow of all mental processes, the specificity of the interaction of representatives of ethnic communities [1, p. 106].

The formation of teaching motifs depends on the national-psychological characteristics (a form of manifestation of an ethnic communit's psychology). The peculiarity of the motivating forces of activity as well as the specificity of motivation and behavior will determine the motivational-background of nationalpsychological characteristics [1, p. 107]. Accordingly, we can assume that the formation of motives depends on the features of motivational background national psychological features.

\section{Methods}

The study of Russian and Chinese motivation and the identification of the dominant motives was carried out using the observation method and the testing method. We adhered to the theoretical propositions of L. I. Bozhovich on the poly-motivated activity and A. I. Savenkova on the dominant motives [6].

In the study we used: 
- Methods of studying the motivation of learning at the university by T. I. Ilina [7].

- Method of determining tolerance for uncertainty by S. Badner, G. U. Soldatova's version (Budner's Scale of Tolerance - Intolerance of Ambiguity) [7].

In addition to testing, each student reported additional information about him/herself, namely the age, school, direction of study, as well as information about the family structure. Students's age was from 18 to 23 years.

\section{Research}

The study involved 174 students, of which were 113 Russian students (74 girls and 39 men) studying at the institutes and universities of the city of Moscow, Penza, and Volgograd (namely, Moscow State Pedagogical University, REU named after G. V. Plekhanov, Moscow National Academy of Arts named after K. A. Timiryazev, MGPPU, MEPI, PenGTU, and VolSU) [4].

Also, we surveyed 27 Chinese students (17 girls, 10 boys) studying at MSU, MPGU, RUDN and 34 Chinese students (13 girls and 21 boys) studying at various educational institutions of China (Shenyang Aerospace University, Dalian University of Technology, Qiqihar University of Liaoning, University of Engineering and Technology, Dalian Ocean University, Shenyang University of Architecture, Liaoning University of Science and Technology, Teachers' College, Shenyang) [8].

Analysis of the research results was conducted in accordance of the method developed by T. I. Ilina.

It was revealed that the students of all three groups are dominated by the motives associated with the "Diploma Degree" (Table 1).

TABLE 1. COMPARATIVE TEST RESULTS OF STUDENTS OF THREE GROUPS (ACCORDING TO THE METHOD OF T. I. ILINA).

\begin{tabular}{|c|c|c|c|}
\hline Indicators & Acquisition of knowledge & Mastering a profession & Getting a diploma \\
\hline Russian students & $33,85 \%$ & $29,37 \%$ & $36,78 \%$ \\
\hline $\begin{array}{c}\text { Chinese students studying } \\
\text { in Moscow }\end{array}$ & $24,46 \%$ & $34,83 \%$ & $39,7 \%$ \\
\hline $\begin{array}{c}\text { Chinese students studying } \\
\text { in China }\end{array}$ & $28,83 \%$ & $34,32 \%$ & $36,85 \%$ \\
\hline
\end{tabular}

The highest score on the "Obtaining a diploma" scale from Chinese students studying in Moscow is related to the fact that in the contemporary labor market in China, bachelors and masters who have studied abroad and returned to their homes are more in demand by employers (in the public sphere and in business).

But, compared to the Chinese students of the two groups, Russian students are more focused on the "Acquisition of knowledge", the lowest indicator on this scale was among Chinese students studying in Moscow.

Chinese students of the two groups fully focus on "Getting a diploma" and "Mastering a profession." This is the motivation for achieving success (achieving success is considered not only a personal need for self-realization, but also the fulfillment of obligations to family and society).

On the "Mastering a Profession" scale, the smallest indicator is among students in Russia. We assume that this is due to the following reasons: Russian students choose a university where they can step over the passing score, being guided by general ideas about their profession, not always knowing that this profession actually requires. The results confirm this statement: the average among first-year students on the "Mastering a profession" scale is 5.78, while the rate of senior students is 4.37 , which is slightly lower than the rate of the first-year students.

Answers on a scale of "Getting a diploma": more than 50\% of the students gave a negative answer to the item 11 ("I think that in our time it is not necessarily to have a higher education") and the positive response to the item 24 ("For me it is very important to have a diploma of higher education"), which added points to the final result. 
To the questions "Which of your inherent qualities would you like to get rid of? Write an answer next to..." and "Which of your inherent qualities do prevent you from studying most of all?" more than $60 \%$ of respondents indicated "laziness." Probably, the motivational sphere of more than half of the test participants are at the transition stage: external motives go inside [6, p. 275]. In fact, such a person is characterized by a lack of interest in the type of activity performed by him/her.

The high score on the "Getting a Diploma" scale from the students of two groups can be explained by the motivation of success that is typical of the Chinese students. Therefore, the difference between the three scales of passed testing is the greatest among Chinese students studying in Moscow. Chinese students who do not have the opportunity to study abroad are more focused on "Mastering the profession" and "Acquiring knowledge", since they have no advantage in having a diploma from a foreign educational institution.

In the course of processing the test results of Chinese students, some interesting features were revealed. These are test questions, to which more than $70 \%$ of participants gave either a positive or a negative answer.

More than $70 \%$ of those tested agreed with the statements: "Examinations must be passed with a minimum of effort" and "I work best when periodically stimulated, urged on," which did not add points to the result on the "Acquisition of knowledge" scale. Disagreement on these points can talk about the irresponsible attitude of Chinese students to study. However, this statement is false. The point is in the understanding of testing assertions by students of different cultures. As a rule, Chinese students always prepare for exams in advance, devoting a large amount of time to homework directly after it has been assigned. Accordingly, before the exam, they do not have to spend a lot of time and effort to prepare. In addition, a control system has been established in educational institutions in China. Even foreign students who study in China and pay for their studies can be expelled if they attend less than $70 \%$ of classes.

First conclusion: The ratio of motives in the learning process depends not only on the personality of students, but also on its values and beliefs. Students in one country have a number of similarities in the motivational sphere.

We would like to provide results of testing students of three groups according to the method of determining tolerance for uncertainty by S. Badner (G. U. Soldatova's version). According to the scores obtained as a result of testing on all scales, the level of intolerance to uncertainty among students of each group is defined as average. In this regard, it is advisable to consider each group in comparison, describing their differences in points within the level itself (Table 2).

TABLE 2. COMPARATIVE RESULTS OF TESTING STUDENTS OF THREE GROUPS ACCORDING TO THE METHOD OF DETERMINING TOLERANCE FOR UNCERTAINTY BY S. BADNER, VERSION OF G. U. SOLDATOVA (IN POINTS).

\begin{tabular}{|c|c|c|c|c|}
\hline Indicators & $\begin{array}{c}\text { Novelty of the } \\
\text { problem }\end{array}$ & $\begin{array}{c}\text { Complexity of the } \\
\text { problem }\end{array}$ & $\begin{array}{c}\text { Unsolvability of } \\
\text { the problems }\end{array}$ & Total points \\
\hline Russian students & 15,38 & 31,53 & 13,5 & 60,41 \\
\hline $\begin{array}{c}\text { Chinese students studying in } \\
\text { Moscow }\end{array}$ & 14,89 & 33 & 10,52 & 58,41 \\
\hline $\begin{array}{c}\text { Chinese students studying in } \\
\text { China }\end{array}$ & 14,47 & 35,12 & 10,32 & 59,91 \\
\hline
\end{tabular}

Indicators on the "Novelty of the Problem" scale do not differ much for students of all groups, the difference between the smallest and the largest ones is only 0.91 points.

The scale "The complexity of the problem": the range of points that determines the average level of this scale is from 21 to 36 points. Thus, the result of students in China stands out, since it is closest to the borderline between medium and high levels. Slightly lower result is Chinese students studying in universities of the capital and the lowest result is among Russian students.

On the scale of the "Insolubility of the Problem," the Russian students' result stands out sharply, while the result of Chinese students in both groups is almost the same.

Second conclusion: Russian students find it easier to cope with tasks that are gradually becoming more comple but already familiar to them, while new tasks increases the level of anxiety of students. In the 
framework of the traditional system of higher education, the emphasis is placed on the development of logical thinking, building logical inferences, identifying and explaining patterns. Students attend lectures, seminars, make presentations, and perform prepared homework in front of an audience. Often, students' initiatives are encouraged, but not creativity. Year by year, the level of difficulty of tasks increases; however, the execution algorithm itself does not change much. Difficult tasks do not always require a creative approach, since the algorithm for their implementation is already known, while tasks of a new type, as well as tasks with a knowingly unknown result, require non-standard decision-making. As a result, students are more willing to perform complex tasks, rather than performing tasks that require creative searching.

The results of the Chinese students of both groups are not very different from each other. The difference in the indicators "Novelty of the problem" and "Insolubility of the problem" is only 0.42 and 0.2 points, respectively. The main difference is only on the scale "The complexity of the problem." This means that the level of anxiety will be somewhat higher if a Chinese student finds the task assigned to him/her difficult, being not new or unresponsive. There is an explanation. Performing any task requires some effort. Recall the distinguishing features of Chinese students' motivation to achieve success, as well as the relationship of external and internal motivation, especially in understanding their abilities and awareness of duty and responsibility to their families and society.

\section{Conclusion}

Based on the study, the following features of the motivational sphere of Russian and Chinese students were identified:

- The motivation of Chinese students is rather defined as the motivation for success, and the motivation of Russian students is the motivation coming from their fear to fail.

- An equally low level of cognitive interest in students from both countries.

- Predominance of a diploma orientation among students in Russia and China.

- A special, excellent understanding of the educational process by Russian and Chinese students.

- Features of students' motivation in Russia and China have an impact on the formation of the educational process' features.

- There is a lack of formation of interest of Russian students to the type of activity they perform.

The hypothesis of our research has been confirmed. Students of different countries are driven by different motives for getting higher education, their formation depends on national psychological characteristics, namely from the motivational and background national psychological characteristics, as well as differences in the culture of societies from different countries.

\section{References}

[1] Krysko, V. G. (2011). Ethnic psychology: study guide for students. Institutions of higher prof. Education. Moscow, Russia: Publishing Center "Academy."

[2] Mikhailova, E. A., Novikova, G. V., Ryabtsev, V. K., Ryashina, V. V. (2016). Moscow University Bulletin. Series 20. Pedagogical education, 4, pp. 78-85.

[3] Murafa, S. V. (2017). Moscow University Bulletin. Series 20. Pedagogical Education, 2, pp. 176-182.

[4] Murafa, S. V., Drozdova, V. A. Moscow (2018). University Bulletin. Series 20. Pedagogical Education, 3, pp. 45-49.

[5] Rean, A. A., Bordovskaya, N. V., Rozum, S. I. (2010). Psychology and pedagogy. St. Petersburg, Russia: Peter.

[6] Savenkov, I. (2009). Pedagogical psychology (volume 2). Moscow, Russia: Publishing Center "Academy." 
[7] Materials on the T. I. Ilina's method and the S. Badner's method (G. U. Soldatova's version). (2018). Retrieved from http://psylab.info/

[8] Site of Shenyang Pedagogical University. (n.d.). Retrieved from http://www.synu.edu.cn/synuen/p1.html.

[9] Bochner, S. (1965). Defining intolerance of ambiguity. Psychological Record, 15(3), pp. 393-400.

[10] Bond, M. H. (2010). Handbook of Chinese psychology. Oxford, UK: Oxford University Press.

[11] Murafa, S. V. (2015). Psychology in Russia: State of the Art, 8(3), pp. 345-352.

[12] Li, J. (李瑾) (2005). Mind or virtue: Western and Chinese beliefs about learning. Current Directions in Psychological Science journal, 14(4), pp. 190-194.

[13] Li, J. (李瑾) (2010). Learning to self-perfect: Chinese beliefs about learning. In Revisiting the Chinese learner (pp. 35-69). The Netherlands: Springer. 